\title{
QUALITY OF LIFE ANALYSIS IN DIABETES MELLITUS TYPE 2 PATIENTS USING MONOTHERAPY AND COMBINATION TREATMENT OF MEDICINE
}

\author{
Imaniar Noor Faridah*, Venty Dewintasari
}

\author{
1.Faculty of Pharmacy, Ahmad \\ Dahlan University. \\ Jl. Prof. Dr. Soepomo, S.H., \\ Janturan, Warungboto, \\ Umbulharjo, Yogyakarta \\ 55164
}

Submitted: 06-02-2017

Revised: 26-02-2017

Accepted: 28-03-2017

*Corresponding author Imaniar Noor Faridah

Email:

imaniar_apt@yahoo.com

\begin{abstract}
Treatment of diabetes mellitus (DM) can be vary, using monotherapy or combination therapy, and it depends on the severity of the disease. That variation will give influences to the patient's clinical condition and also their quality of life (QoL). The objective of this study is to determine the average of QoL's score in DM patients who use monotherapy and combination therapy of antidiabetic oral in Public Health Center of Kotagede 1 Yogyakarta. This study was conducted in a cross sectional study. Subjects were people who had an age above 18, got the diagnose of DM type 2, and also consumed of oral antidiabetic monotherapy or combination. The measurement of QoL is using a DQLCTQ questionnaire in Bahasa Indonesia. Analysis statistic with independent sample T-test was used to determine the differences between QoL in patients who use monotherapy and combination. Subjects who met the inclusion criteria are 52 patients. About $82.70 \%$ (43 patients) of the patients used combination and the other ( 9 patients) used monotherapy. The average of QoL in monotherapy patients (78.95 \pm 11.36$)$ was higher than in combination therapy's (75.18 \pm 10.57 ). Result of the analysis statistic showed that there is no significant differences (p0.095) of QoL between monotherapy and combination therapy patients.
\end{abstract}

Keywords: Diabetes mellitus, DQLCTQ, monotherapy, combination

\section{INTRODUCTION}

Quality of life (QoL) is measured by individual perceptions on various aspects such as physical, emotional, and social aspect. The differences on each particular aspects influenced by ethnic, culture, education, and also income (Myers et al., 2013; Nagpal et al., 2010). Other than that, quality of life also affected by chronic disease. Some studies showed that patients with chronic disease have an average of quality of life lower than healthy patients (Bonomi et al., 2000).

Diabetes mellitus is a chronic disease that increase significantly year by year. Data from International Diabetes Federation in 2013 showed that Indonesia was a country which have amount of people with diabetes (20-79 years old) for about 8.5 millions (International Diabetes Federation, 2013). Different with that, according to International Diabetes Federation in 2015 , total cases of adults (20-79 years old) with diabetes is about 10 million cases (International
Diabetes Federation, 2015). The increasing of amount of diabetes patients needs an attention from many people and adequate of management therapy, which are including selfmonitoring blood glucose, exercise, dietary modifications, and also adherence of the medications (Sharma et al., 2014). In order to get a better glycemic index, it requires appropriate therapeutic management, and also it can be a preventive from the complications and with the hope of increasing patient's quality of life.

Treatment of diabetes mellitus patients can be vary using monotherapy or combination therapy, and it depends on the severity of the disease from each person. The treatment that used by the patients will give influences to the patient's clinical condition and also their quality of life. Previous study showed that the increase of complexity regimen in diabetes patients was needed to get a better glycemic control, however the measurement of QoL showed that 
patients felt physical inconvenience caused by the increasing of complexity regimen (Lau et al., 2004).

There are many kinds of avalailable instruments for assessing quality of life, including generic and disease-specific which in this study is diabetes-specific. Generic instruments are designed to assess aspects on health that universal, and different with that, disease-specific instrument more detailed and accurate to measure specific impacts of health. The Diabetes Quality of Life Clinical Trial Questionnaire (DQLCTQ) is one of disease-specific instrument that has been validated, reliable and comprehensive to measure quality of life (Shen et al., 1999; Garratt et al., 2002).

The objective of this study is to determine the average of quality of life's score in diabetes mellitus patients who use monotherapy and combination therapy of antidiabetic oral in Public Health Center of Kotagede 1 Yogyakarta.

\section{MATERIAL AND METHODS}

Ethics Clearance was granted by the Ethics Committee of Ahmad Dahlan University with approval No.011601013. Informed consent paper was obtained from all participants.

\section{Study design}

This study was a cross sectional study which was conducted between February and March 2016 in Public Health Center of Kotagede 1 Yogyakarta, Indonesia.

\section{Participants}

The subjects on this study were diabetes mellitus patients' who came to Public Health Center of Kotagede 1 between February March 2016. The inclusion criterias of this study were patients who had an age above 18 years old, got the diagnose of diabetes mellitus type 2 and attended to the public health center of Kotagede 1 Yogyakarta, consumed of oral antidiabetic monotherapy or combination, and also willing to be a participants. The exclusion criteria in this study was people who did not filled the questionnaire completely. The amount of patients that met the inclusion criterias was 52 patients.

\section{Questionnaire}

Patients who met the inclusion criteria and willing to be a participant will get a questionnaire. Measurement of quality of life in this study using a Diabetes Quality of Life Clinical Trial Questionnaire (DQLCTQ) in Bahasa Indonesia version. DQLCTQ has 8 aspects included physical, energy, health distress, mental health, satisfaction, treatment satisfaction, treatment flexibility, and frequency of symptoms. The measurement of quality of life in DQLCTQ questionnaire using a scale from 0 to 100 , which are higher score indicates better quality of life. DQLCTQ questionnaire has been validated in previous study (Shen et al., 1999).

\section{Statistical Analysis}

Analysis statistic with independent sample T-test was used to determine the differences between quality of life in patients who use oral antidiabetic monotherapy and combination therapy.

\section{RESULT AND DISCUSSION}

A number of 52 patients who met the inclusion criteria have characteristics (Table I). Table I showed that $75 \%$ of patients (39) was female, and 50\% (26 patients) had ages over 60 years old. Data on this study was different with data from IDF in 2013 which are about 14 million more men than women with diabetes, and the ages of almost half of all adults with diabetes are between 40-59 years old (International Diabetes Federation, 2013). These differences can be occured due to the insufficient number of participants in this study.

The types of medicine divided into 2 groups which were monotherapy in 9 patients $(17.3 \%)$ and combination therapy in 43 patients $(82.7 \%)$. In diabetes mellitus, metformin is an optimal drug for monotherapy, however, if the monotherapy cannot reach the glycemic target, initial combination between metformin plus a second agent can be used to achieve the HbA1C target more quickly (Inzucchi et al., 2015). These data also can be linked with the duration of the disease since diagnosis, which were $65.4 \%$ (34 patients) had disease duration since more than 3 years ago. Besides that, the impact of diabetes mellitus is comorbidities, and $69.2 \%$ (36 patients) in this study have comorbidities. 
Table I. Patient's characteristic

\begin{tabular}{lc}
\hline \multicolumn{1}{c}{$\begin{array}{c}\text { Patient's } \\
\text { Characteristic }\end{array}$} & $\begin{array}{c}\text { Number of } \\
\text { Patients } \mathbf{n = 5 2}(\mathbf{\%})\end{array}$ \\
\hline Sex & \\
Male & $13(25 \%)$ \\
Female & $39(75 \%)$ \\
Age & \\
$<40$ & $4(7.70 \%)$ \\
$41-60$ & $22(42.3 \%)$ \\
$>60$ & $26(50.0 \%)$ \\
Educational Level & \\
No education & $9(17.3 \%)$ \\
$<$ Senior High School & $26(50.0 \%)$ \\
> Senior High School & $17(32.7 \%)$ \\
Marietal status & \\
Not married & $1(1.9 \%)$ \\
Married & $37(71.2 \%)$ \\
Divorce/Widow(ed) & $14(26.9 \%)$ \\
Duration since diagnosis & \\
$<1$ year & $1(1.9 \%)$ \\
1-3 years & $17(32.7 \%)$ \\
$>3$ years & $34(65.4 \%)$ \\
Type of Medicine & \\
Monotherapy & $9(17.3 \%)$ \\
Combination therapy & $43(82.7 \%)$ \\
Comorbidities & \\
Yes & $36(69.2 \%)$ \\
No & $16(30.8 \%)$ \\
\hline
\end{tabular}

Table II showed about the use of antidiabetic oral in this study. A number of 43 patients $(82.70 \%)$ use combination therapy, which were all of them use metformin as a first therapy and use sulphonylurea as an additional therapy. Metformin, a biguanides which can reduce the hepatic glucose, is the optimal drug for monotherapy. Its advantages were low cost, minimal side effect of hypoglycemia, and can reduce the CVD events (Inzucchi et al., 2015). The additional therapy were sulphonylurea including glimepiride and glibenclamid. The patients who use glimepiride was higher than glibenclamid. A randomized controlled trial study which compared the effect of glimepiride and glibenclamid on blood glucose in normal man showed that in fasting state there were similar effect on blood glucose level after IV administration of glibenclamid and glimepiride, and different with that, in post-prandial state (3-5h) blood glucose was significanly higher after glibenclamide than after glimepiride administration (Raptis et al., 1999).
Table II. The use of antidiabetic oral in diabetes type 2 patients

\begin{tabular}{lcc}
\hline Medicines & Sum & $\mathbf{\%}$ \\
\hline Monotherapy & & \\
Metformin & 8 & $15,38 \%$ \\
Glimepiride & 1 & $1,92 \%$ \\
Glibenclamid & 0 & 0 \\
Total & 9 & $17,30 \%$ \\
Combination therapy & & \\
Metformin + Glimepiride & 41 & $78,85 \%$ \\
Metformin + Glibenclamid & 2 & $3,85 \%$ \\
Total & 43 & $82,70 \%$ \\
\hline
\end{tabular}

Quality of life analysis (Table III) showed that the average of quality of life in monotherapy patients was higher that in patients who use combination therapy, although that was not significantly different $(p=0.095)$. The result of this study was similar with previous study in hospital of Yogyakarta in 2011, which the average of quality of life in monotherapy patients was higher than in combination therapy, and it was significantly different $(\mathrm{p}=0.002)$ (Sari et al., 2011).

The endpoints of diabetes mellitus from the UK Prospective Diabetes Study (UKPDS) are reducing the achieved $\mathrm{HbA1C}$ of $7.0 \%$ (for intensive treatment group) versus $7.9 \%$ (for conventional treatment group), reducing microvascular endpoints (retinopathy, nephropathy, and neuropathy), and decreasing the need of laser treatment and catarac surgery (UK Prospective Diabetes Study, 1998). If the use of monotherapy can reduce the blood glucose and find the target of glycemic index, patients will get the benefit and increase their quality of life.

Furthermore, the result from table III showed that patients who use monotherapy had a good score in physical function, energy, health distress, mental health, satisfaction, treatment flexibility, and frequency of symptoms. It has been known that diabetes has negative impact on physical, psychological, and social functioning (Koopmanschap, 2002). Stress and coping with diabetes can affect the severity of the disease directly, also with pathophysiological processes and patient's perception of illness will affect to the patient's adherence and daily functioning. 
Table III. Analysis QoL between monotherapy and combination therapy

\begin{tabular}{|c|c|c|c|}
\hline \multirow{2}{*}{ Quality of Life Domain } & \multicolumn{2}{|r|}{ Type of therapy } & \multirow{2}{*}{$p$ value } \\
\hline & Monotherapy $(n=9)$ & Combination therapy $(n=43)$ & \\
\hline Physical Function & $91.11 \pm 13.6$ & $73.02 \pm 17.3$ & $0.005^{*}$ \\
\hline Energy & $78.67+12.2$ & $71.72+10.5$ & 0.850 \\
\hline Health Distress & $81.78+8.02$ & $78.60+9.9$ & 0.376 \\
\hline Mental Health & $82.22 \pm 11.2$ & $77.21 \pm 9.5$ & 0.170 \\
\hline Satisfaction & $76 . \overline{9} \pm 7.6$ & $73.13 \pm 6.3$ & 0.207 \\
\hline Treatment Satisfaction & $72.84 \pm 14.2$ & $83.46 \pm 9.5$ & $0.008^{*}$ \\
\hline Treatment Flexibility & $69.44 \pm 10.5$ & $68.37 \pm 8.5$ & 0.742 \\
\hline Frequency of Symptoms & $79.37 \pm 13.6$ & $75.95 \pm 13.1$ & 0.484 \\
\hline Total QoL & $631.62 \pm \overline{9} 0.92$ & $601.46 \pm 84.6$ & 0.095 \\
\hline Average of QoL & $78.95+11.36$ & $75.18 \pm 10.57$ & 0.095 \\
\hline
\end{tabular}

Note $*=$ Significantly differences $(\mathrm{p}<0.05)$

There are 2 domains that different significantly, including physical function and treatment satisfaction domains. Physical function score in monotherapy patients was higher than in combination therapy patients, it can be happened because the monotherapy patients were not feel restricted in their daily activities. This differences were statistically different with the significant value 0.005 $(\mathrm{p}<0.05)$.

The use of combination treatment in diabetes mellitus type 2 patients is if non insulin monotherapy at maximal tolerated dose does not achieve or maintain $\mathrm{HbA} 1 \mathrm{C}$ target over 3 months. Other than that, increasing the physical activity also important to get the HbA1C target before adding another oral agent (ADA, 2016). Thus, patients who use combination therapy are patients who cannot maintain their glicemic index and needed additional treatment.

Other, in the treatment satisfaction domain, the score of patients who use combination therapy was higher than monotherapy patients, and it was statistically different that proved by the significant value which is $0.008(\mathrm{p}<0.05)$. This data was different with the previous study, which were score of treatment satisfaction domain in combination therapy patients was lower than in monotherapy patients $(\mathrm{p}=0.645)$ (Sari et al., 2011). The meaning of this result was combination therapy patients feel satisfied with their treatment.
Combination therapy is given to patients who cannot adequately decrease the blood glucose with monotherapy. In this study, quality of life higher in combination therapy patients than in monotherapy, which means that patients can feel the positive impact from the combination therapy. Result from different study, in patients with unresectable or metastatic cutaneous BRAF Val600-mutationpositive melanoma (COMBI-v) showed the results that treatment with combination of dabrafenib plus trametinib gives a benefit rather than with monotherapy vemurafenib (Grob 2015).

Furthermore, other domains such as energy, health distress, mental health, satisfaction, treatment flexibility, and frequency of symptoms were not different statistically between monotherapy and combination therapy patients. All of their score were higher in monotherapy than in combination therapy.

Finally, limitation of this study was the insufficient number of participants and it made an impact to the quality of life's score. In order to improve this study, the number of participants should be increased and balanced between monotherapy and combination therapy patients. Others, a lot of factors that can affect to the quality of life, such as comorbidity, absence of adverse event, Body Mass Index (BMI), or emotional patients which should be added in the next study. 


\section{CONCLUSION}

From this study, we found that there is no significant differences ( $p$ 0.095) of quality of life between monotherapy patients and combination therapy patients.

\section{ACKNOWLEDGEMENTS}

The authors thank to the patients who have willingness to be participants in this study, and to the heads and staffs of the Public Health Center of Kotagede 1 Yogyakarta who helped the researcher for getting the data in this study.

\section{REFERENCES}

American Diabetes Association (ADA), 2016, Standards of Medical Care in Diabetes, Diabetes Guidelines Summary Recommendations from NDEI, Diabetes Care, 2016;39(suppl 1):S1-S106.

Bonomi AE., Patrick DL., Bushnell DM., Martin M, 2000, Validation of the United States' version of the World Health Organization Quality of Life (WHOQOL) instrument, J. Clin. Epid. 53 : 19-23.

Garratt AM., Schmidt L., Fitzpatrick R., 2002, Patient-assessed health outcome measures for diabetes : a structured review, Diabetes Medicine 19; 1-11.

Grob JJ., Amonkar MM., Karaszewska B., Schachter J., Dummer R., et al, 2015, Comparison of dabrafenib and tremetinib combination therapy with vemurafenib monotherapy on healthrelated quality of life in patients with unresectable or metastatic cutaneous $B R A F V$ al600-mutation-positive

melanoma (COMBI-v): result of a phase 3, open-label, randomised trial, The Lancet Oncology October 2015, Volume 16, No.13, p1389-1398.

International Diabetes Federation, 2013 , IDF Diabetes Atlas Sixth Edition, www.idf.org/diabetesatlas.

International Diabetes Federation, 2015, Diabetes in Indonesia, http:// www.idf. org /membership/wp/indonesia.
Inzucchi SE., Bergenstal RM., Buse JB., Diamant M., Ferrannini E., et al., 2015, Management of Hyperglycemia in Type 2 Diabetes, 2015 : A PatientCentered Approach. Update to a Position Statement of the American Diabetes Association and the European Association for the Study of Diabetes, Diabetes Care 2015 ;38: 140-149.

Koopmanschap M., 2002, CODE-2 Advisory Board Coping with Type II diabetes : the patient's perspective, Diabetologia, 2002,45(7):S18-22.

Lau CY., Qureshi AK., Scott SG., 2004, Association between glycaemic control and quality of life in diabetes mellitus, $J$ Postgrad Med 50 : 189-94.

Myers VH., McVay MA., Brashear MM., Johannsen NM., Swift DL. et al., 2013, Exercise Training and Quality of Life in Individuals with Type 2 Diabetes, Diabetes Care 36 : 1884-1890.

Nagpal J., Kumar A., Kakar S., Bhartia A., 2010, The Development of 'Quality of Life Instrument for Indian Diabetes Patients (QOLID) : A Validation and Reliability Study in Middle and Higher Income Groups, JAPI 58 : 295304.

Raptis SA., Hatziagelaki E., Dimitriadis G., Draeger KE., Pfeiffer C., Raptis AE., 1999, Comparative Effect of Glimepiride and Glibenclamide on Blood Glucose, C-peptide and insulin concentrations in the fasting and postprandial state in normal man, Experimental and Clinical Endocrinology \& Diabetes 107 (1999):350355.

Sari RM., Thobari JA., Andayani TM., 2011, Evaluation Quality of Life of Type 2 Diabetic Patients With Oral Antidiabetic Therapy at Ambulatory Clinic in RSUP Dr. Sardjito, JMPF Vol.1 No.1 : 35-42.

Sharma T., Kalra J., Dhasmana DC., Basera H., 2014, Poor Adherence to Treatment : A major challenge in diabetes, Journal Indian Academy of Clinical Medicine 15 (1) : 26-9. 
Shen W., Kotsanos JG., Huster WJ., Mathias SD., et al., 1999, Development and Validation of the Diabetes Quality of Life Clinical Trial Questionnaire, Med Care, 1999 Apr;37(4Suppl Lilly):AS45-66.
UK Prospective Diabetes Study (UKPDS) Group, 1998, Intensive Blood Glucose Control with Sulphonylurea or insulin compared with conventional treatment and risk of complications in patients with type 2 diabetes (UKPDS 33), Lancet, 1998; 352:837-853. 